BGPE Discussion Paper

No. 126

\title{
Good Intentions Pave the Way to ... the Local Moneylender
}

\author{
Lutz G. Arnold \\ Benedikt Booker
}

September 2012 


\title{
Good Intentions Pave the Way to ... the Local Moneylender*
}

\author{
Lutz G. Arnold (corresponding author)
} Benedikt Booker

\author{
University of Regensburg \\ Department of Economics \\ 93040 Regensburg, Germany \\ Phone: +49-941-943-2705 \\ Fax: +49-941-943-1971
}

E-mail: lutz.arnold@wiwi.uni-regensburg.de

\begin{abstract}
Microborrowers may take usurious loans to repay a loan taken from a microfinance institution because of having neglected the time inconsistency of optimal plans or having discounted future payoffs too strongly from the ex-post perspective. Microfinance programs should strive at preventing such consequences of bounded rationality.

JEL classification: G21, D91
\end{abstract}

Key words: microfinance, hyperbolic discounting

*Financial support from the Deutsche Forschungsgemeinschaft (DFG) through grant AR 530/1-1 is gratefully acknowledged. 


\section{Introduction}

In a much-discussed newspaper article, Gokhale (2009) has brought wide attention to the fact that moneylending, at very high interest rates and often using harsh methods of enforcing repayment, coexists with microfinance (MF) when and where the latter flourishes. For one thing, this is due to the fact that demand exceeds microfinance institutions' (MFIs') lending capacity in some places and that the two types of lenders specialize in different segments of the growing market for small loans to the poor. However, as indicated by Gokhale (2009), it is also part of moneylenders' (MLs') business to make loans to MFI clients in need of liquidity as their MFI loans come due, thereby adding to the problem of over-indebtedness.

The reply of standard economic theory is: even if, so what? If someone uses an ML loan to repay an MFI loan, this reflects the fact that the opportunities provided by the new loan are worth bearing the burden of repayment or default on the new loan; if she decides to take the MFI loan in the first place, this means that the prospective returns outweigh the associated risks ex ante. Yet, as in similar contexts, this reply of standard economic theory misses the point if borrowers have present-biased preferences (Laibson, 1997; O'Donoghue and Rabin, 1999). In that case, the borrower may not act in her own best interest: she may plan to follow a decision path which turns out to be time-inconsistent and revise her plans; or, if her present bias is "an error" (O'Donoghue and Rabin, 2003, 187), she might regret decisions made at early decision points. The present paper presents a model which shows that either of these two sorts of bounded rationality can cause a micro-borrower to inadvertently end up with an ML loan.

\section{Motivation}

That the surge in MF has not replaced traditional moneylending activity, or even reduced it in absolute terms, is a stylized fact in development economics. Gokhale (2009) backs up her argument with a figure taken from RBI $(2007,5)$ : the share of MLs in rural household debt in India rose from 17.5 percent in 1991 to 29.6 percent in 2002. Robinson (2001, 176-177) reports even higher market shares, often above 50 percent, for several other emerging economies and developing countries. Micro-level studies show that individual borrowers are often active both in the formal and in the informal loan markets (which besides commercial MLs comprise mutual aid groups and family and friends; see Robinson, 2001, 173). In Sinha and Matin's (1998, 69) and Jain and Mansuri's (2003, Table 1, 258) studies of Bangladeshi villages, for instance, more than three-fourths of the (land-poor) households in the MFIs' target group also took at least one informal loan. 
While, traditionally, MLs were lumped together as usurious monopolists, several studies point out that some of them play a productive role in rural credit markets (Robinson, 2001, 180; RBI, 2007, 25; Giné, 2011) and even help overcome information and enforcement problems in conjunction with MFIs (Rahman, 1992, 153; RBI, 2007, 30; Jain and Mansuri, 2003). Still, there is no doubt that the traditional malicious type is frequent in the spectrum of MLs: "Whether malicious moneylenders exist is not a question of myth or reality. They are real, as anyone who has lived in undeveloped parts of rural India, for example, can testify" (Robinson, 2001, 181). The much bemoaned comeback of commercial MLs in Andhra Pradesh after the legal curtailment of MFI activity in 2010 is a recent reminder (Ballem et al., 2011).

"Debt cycles" (Rahman, 1992, 79) resulting from taking new loans to repay old ones coming due are widespread in this environment. Many observers have pointed out that 95 percent repayment rates on MFI loans could not be maintained without cross-borrowing from informal sources (Chavan and Ramakumar, 2002, 960). Consistent with this argument, default rates are substantially higher for virtually all other kinds of finance. Zeller et al. (2001, Table 4.12, 59) report a 62 percent default rate on non-MFI formal loans compared to below 7 percent for the Grameen Bank. In the Bangladeshi village investigated by Sinha and Matin (1998, Table 4, 75) target group households with an MFI loan use a startling 45 percent of the money they borrow informally to repay MFI debt. Figures of around 10-15 percent are reported by Sinha and Matin (1998, Table 4, 75) for the relatively less poor non-target group MFI borrowers, by Zeller et al. (2001, Table 4.10, 57), and by Jain and Mansuri (2003, Table 3, 260) for small informal loans. Field studies provide telling evidence: Rahman $(1999,77)$ reports the case of a household which "became heavily indebted not only to the [Grameen] Bank but also to moneylenders in the village"; and Woolcock $(1999,28)$ recounts the case of a woman who explains in a group meeting "how the shame of not being able to repay her Grameen loan had driven her to the local moneylender, which in the long run had only intensified the desperation of her situation".

Thus, usurious MLs coexist with MFIs and are used to repay them. Still, the view that "borrowers end ... up worse off both relatively and absolutely through their involuntary participation in the informal markets" (Rahman, 1992, 156) cannot be reconciled with purely rational decision making. In what follows, we show that a model with present-biased borrowers can be used to put the argument on solid grounds. 


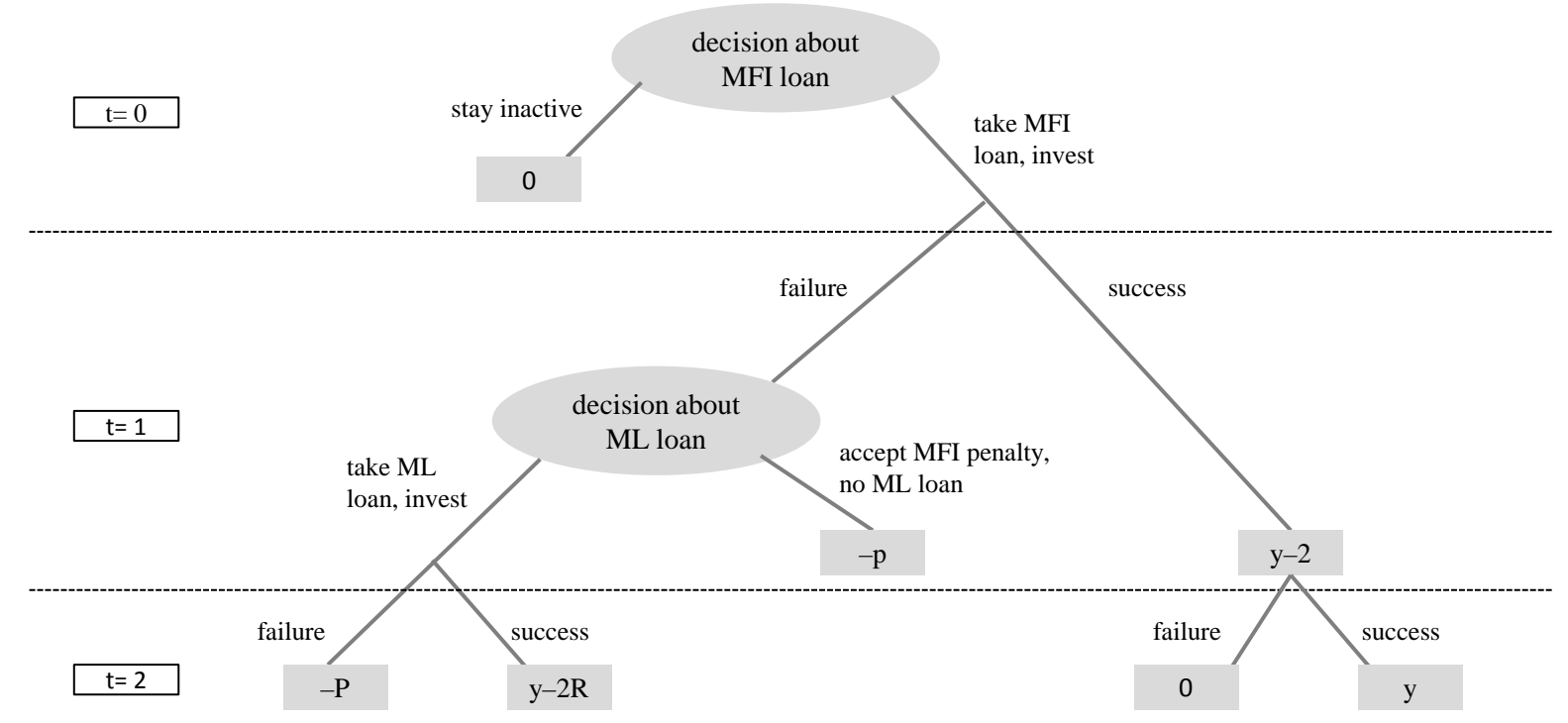

Figure 1: Decision tree

\section{Model}

There are three dates $t=0,1,2$. At date 0 , a micro entrepreneur is endowed with an investment project, which requires one unit of capital. She has no equity or collateral. An MFI offers her a loan to finance the project. We focus on situations in which she repays the loan with certainty, so there is no default risk, and (ignoring transaction costs) the MFI charges no interest: the contractual repayment is unity. The borrower decides whether to stay inactive (which yields zero payoff) or take the MFI loan and invest. The project succeeds with probability $\pi(0<\pi<1)$ and fails with probability $1-\pi$. If it succeeds, it yields payoff $y(>2 / \pi)$ at date 1 , otherwise the payoff is zero. The borrower is endowed with the same project at $t=1$. If the project started at $t=0$ succeeds, she repays one unit of income to the MFI, uses another unit of income to start the new project, and consumes $y-2$. At date 2 , she consumes $y$ or nothing, depending on whether the second project succeeds or fails. If the project started at $t=0$ fails, she decides whether to default on the MFI loan or take a loan from an ML, use this loan to repay the MFI, and start the new project at date 1. If she defaults on the MFI loan, she faces a penalty $p(>0)$. The (exogenous) gross interest on the ML loan is denoted $R(>1 / \pi)$. At date 2 , the borrower repays $2 R$ and consumes $y-2 R$ $(>0)$ if her second project succeeds and faces a penalty $P(>p)$ if it also fails (see Figure 1). Both penalties are taken as exogenously given. The borrower does not have access to consumption loans, which help adapt her consumption profile to her time preference. 
We analyze the model for two different specifications of boundedly rational decision making. In both cases, the borrower is risk-neutral and present-biased. Date- $t$ utility $c_{t}$ is the difference between consumption and the penalty taken at $t(=1,2)$. In Section 4 , perceived utility is $U_{0}=\beta\left(\delta c_{1}+\delta^{2} c_{2}\right)$ as of date 0 and $U_{1}=c_{1}+\beta \delta c_{2}$ as of date 1 , where $\delta(\leq 1)$ is the usual one-period discount factor and $\beta(<1)$ is the additional discount factor introduced by Laibson (1997) for "everything that is in the future". The borrower is said to be naive if at date $t(=0,1)$, she plans to take the current and future actions which maximize $U_{t}$, ignoring possible time inconsistency. She is sophisticated if she maximizes utility subject to the time consistency constraint, i.e., if she solves the problem backward anticipating future optimal decisions (O'Donoghue and Rabin, 1999). In Section 5, perceived utility is $U_{0}=c_{1}+\beta \delta c_{2}$ at date 0 and $U_{1}=c_{1}+\beta \delta c_{2}$ at date 1 . That is, dates 0 and 1 are so close together (compared to dates 1 and 2) that there is no discounting (or, equivalently, all the action going on at dates 0 and 1 in the former model takes place at one date here). The borrower solves her utility maximization problem backward. Following O'Donoghue and Rabin (2003), the present bias implied by $\beta<1$ is now interpreted as an error. The borrower's true preferences are obtained by setting $\beta=1$.

\section{Naive versus sophisticated investment behavior}

Rather than discuss all possible outcomes of the borrower's decision process, we focus on the most worrisome case: we show that it may happen that the naive borrower takes the MFI loan, planning to accept the MFI penalty in case of failure of her project, but then revises her plan and repays the MFI loan with a new loan from the ML, even though she would not have taken the MFI loan in the first place if she had held correct beliefs about her future behavior.

Suppose the borrower is naive. She plans at $t=0$ to accept the MFI penalty $p$ at $t=1$ if the investment project fails if, and only if,

$$
\beta \delta^{2}[(1-\pi)(-P)+\pi(y-2 R)]<\beta \delta(-p) .
$$

Given the plan to accept the penalty, she takes the MFI loan at $t=0$ if, and only if,

$$
\beta \delta[(1-\pi)(-p)+\pi(y-2)]+\beta \delta^{2} \pi^{2} y>0 .
$$

It turns out that the plan to accept the penalty is time-inconsistent and the borrower takes the ML loan in order to repay the MFI loan and invest again if, and only if,

$$
\beta \delta[(1-\pi)(-P)+\pi(y-2 R)]>-p .
$$


If she were sophisticated, she would anticipate her decision not to accept the MFI penalty. She would then not take the MFI loan in the first place if, and only if,

$$
\beta \delta^{2}\left[(1-\pi)^{2}(-P)+(1-\pi) \pi(y-2 R)\right]+\beta \delta \pi(y-2)+\beta \delta^{2} \pi^{2} y<0 .
$$

Proposition 1: Let

$$
\frac{p}{\beta \delta}>(1-\pi) P-\pi(y-2 R)>\frac{\pi}{1-\pi} \frac{y-2+\delta \pi y}{\delta}>\frac{p}{\delta} .
$$

Then the naive investor takes the (interest-free) MFI loan at $t=0$ and the $M L$ loan at $t=1$ if her project fails, though she would not take a loan if she were sophisticated.

Proof: The inequalities in the proposition imply the validity of the inequalities (1)-(4).

Under the conditions of Proposition 1, the naive borrower ends up with an ML loan because of having taken a fair MFI loan (and having had bad luck). In order for this situation to arise, the present bias has to be sufficiently strong: $\beta$ has to be small enough so that the ends of the chain of inequalities in the proposition are sufficiently disparate. Given this, the ML penalty $P$ has to be small enough so that the borrower does not accept the MFI penalty (first inequality) but at the same time large enough so that after failure of her project she regrets having taken the MFI loan (second inequality).

One might object that the MFI loan is not causal for the taking the ML loan, since the borrower would also take the ML loan in the absence of an MFI. To address this objection, suppose the borrower can take an ML loan at gross interest $R$ to carry out the investment project at date 0 . If it succeeds, she repays, reinvests, and consumes $y-R-1$ at date 1 and $y$ at date 2 if the second project also succeeds; if it fails, the penalty $P$ applies at date 1 . Then the borrower does not invest if, and only if, $(1-\pi) P-\pi(y-2 R)>\delta \pi^{2} y+\pi(R-1)$. Given this additional restriction, the MFI loan is causal for taking the ML loan.

\section{Sophisticated versus rational investment behavior}

Next, suppose the borrower is sophisticated, but interpret her present bias as an error. Again, we do not analyze all possible cases comprehensively. We show that the borrower may end up with an ML loan, even though she would not if she acted in line with her true preferences.

Condition (3) implies that the borrower takes the ML loan if the project financed using the MFI loan fails. Consider now the case in which the sophisticated borrower invests at date 0 . With no discounting between dates 0 and 1 and given (3), this requires

$$
\beta \delta\left[(1-\pi)^{2}(-P)+(1-\pi) \pi(y-2 R)\right]+\pi(y-2)+\beta \delta \pi^{2} y>0 .
$$


If the borrower were rational, she would take the MFI penalty at date 1 if, and only if,

$$
\delta[(1-\pi)(-P)+\pi(y-2 R)]<-p .
$$

Proposition 2: Let

$$
\min \left\{\frac{p}{\beta \delta}, \frac{\pi}{1-\pi} \frac{y-2+\beta \delta \pi y}{\beta \delta}\right\}>(1-\pi) P-\pi(y-2 R)>\frac{p}{\delta} .
$$

Then the sophisticated investor takes the (interest-free) MFI loan at $t=0$ and the $M L$ loan at $t=1$ if her project fails. If she were rational, she would either accept the MFI penalty in case of failure or not take the MFI loan in the first place.

Proof: The inequalities in the proposition imply the validity of (3), (5), and (6). If

$$
\frac{\pi}{1-\pi} \frac{y-2+\pi \delta y}{\delta}>\frac{p}{\delta}
$$

she takes the loan and accepts the penalty in case of failure for $\beta=1$. Otherwise, the rational investor stays inactive at $t=0$.

The interpretation of the inequalities in the proposition is similar as for Proposition 1. There are two different possible reasons for regret: not having taken the MFI penalty or having taken the MFI loan in the first place.

\section{Conclusion and outlook}

From the fact that a microborrower ends up with a loan from a moneylender we must not conclude that she acted in her best interest ex ante. She might have neglected the time inconsistency of her plans or regret having discounted future payoffs too strongly.

The main policy implication for MF markets is that financial literacy should be more than a buzzword in MF programs and should not focus exclusively on financial payoffs but also on the process of sequential decision making. Loan officers should not be incentivized to maximize outreach (Rahman, 1999, 79), but provide assistance in making sound decisions whether or not to take a loan.

The most promising direction for future research is to analyze the interaction of present-biased borrowers, benevolent MFIs, and malicious MLs using the mechanism design approach (Townsend, 2003). The model of Section 4 illustrates that present bias and usurious ML activity potentially have an important impact on the solution to an MFI's contracting problem: suppose the purpose of the MFI penalty is to solve an enforcement problem. Incentive compatibility implies $p \geq 1$. Suppose 
the inequalities in Proposition 1 are satisfied for $p=1$. Then the borrower takes the ML loan in order to repay the MFI in case of failure of her project (since (3) holds) for all admissible $p$. It follows that she would not take the loan if she were sophisticated (since (4) holds irrespective of the magnitude of $p$ ). So it is optimal not to offer her a loan - the presence of the ML makes it infeasible to overcome the enforcement problem by means of a non-pecuniary penalty. In the absence of an ML, the MFI would offer a loan with repayment $1 / \pi$ and penalty $p=1 / \pi$ to the borrower if

$$
\frac{\pi}{1-\pi} \frac{\pi y-(1+\pi)+\delta \pi^{2} y}{\delta}>\frac{1}{\delta}
$$

so that the expected gain of taking the loan $\beta \delta[(1-\pi)(-1 / \pi)+\pi(y-1 / \pi-1)]+\beta \delta^{2} \pi^{2} y$ is positive. A more extensive analysis would probably yield important insights into how to design contracts in such a way that borrowers get access to finance without inadvertently ending up with an ML loan.

\section{References}

Ballem, A., George, D., Mohammad, G. A., Kappor, R., Chakraborty, A., Venkata, N. A., 2011. What Are Clients Doing Post the Andhra Pradesh MFI Crisis? Research Paper, MicroSave.

Chavan, P., Ramakumar, R., 2002. Micro-Credit and Rural Poverty: An Analysis of Empirical Evidence. Economic and Political Weekly 37, 955-965.

Giné, X., 2011. Access to capital in rural Thailand: An estimated model of formal vs. informal credit. J. Devel. Econ. 96, 16-29.

Gokhale, K., 2009. As Microfinance Grows in India, So Do Its Rivals. WSJ, December 15.

Jain, S., Mansuri, G., 2003. A little at a time: the use of regularly scheduled repayments in microfinance programs. J. Devel. Econ. 72, 253-279.

Laibson, D., 1997. Golden Eggs and Hyperbolic Discounting. Quart. J. Econ. 62, 443-477.

O’Donoghue, T., Rabin, M., 1999. Doing it Now or Later. Amer. Econ. Rev. 89, 103-124.

O’Donoghue, T., Rabin, M., 2003. Studying Optimal Paternalism, Illustrated with a Model of Sin Taxes. Amer. Econ. Rev., Papers and Proceedings 93, 186-191.

Rahman, Am., 1999. Micro-credit Initiatives for Equitable and Sustainable Development: Who Pays? World Devel. 72, 253-279. 
Rahman, At., 1992. The Informal Financial Sector in Bangladesh: An Appraisal of its Role in Development. Devel. Change 23, 147-168.

RBI, 2007. Report of the Technical Group to Review Legislation on Money Lending. Mumbai: Reserve Bank of India.

Robinson, M. S., 2001. The Microfinance Revolution: Lessons from Indonesia. Washington, D.C.: World Bank.

Sinha, S., Matin, I., 1998. Informal Credit Transactions of Micro-Credit Borrowers in Rural Bangladesh. IDS Bulletin 29, 66-80.

Townsend, R. M., 2003. Microcredit and Mechanism Design. J. Europ. Econ. Assoc. 1, 468-477.

Woolcock, M. J. V., 1999. Learning from Failures in Microfinance: What Unsuccessful Cases Tell Us About How Group-Based Programs Work. Amer. J. Econ. Sociology 58, 17-42.

Zeller, M., Sharma, M., Ahmed, A. U., Rashid, S., 2001. Group-Based Financial Institutions for the Rural Poor in Bangladesh: An Institutional- and Household-Level Analysis. Research Report 20, International Food Policy Research Institute. 